José de Coca

Leicher

Marta García Carbonero
Profesor Ayudante

Doctor, Departamento Ideación Gráfica, ETSAM-UPM.

Profesora

Ayudante Doctora,

Departamento

de Composición

Arquitectónica,

ETSAM-UPM.

\section{Paisaje de interior Estrategias proyectuales para habitar el bancal}

\author{
Keywords: Casa de Campo fair grounds, landscape, terrace, Cabrero, Corrales, Molezún, Sota
}

Spain's abrupt topography has fostered the stepped arrangement of many agrarian estates, articulating landscapes where retaining walls shape the ground while they determine the way the site is inhabited. Vernacular construction has provided different solutions to these problems, but terraced slopes have also inspired more recent designs that adapt to the contours of the site avoiding large excavations. That was the case of some of the architecture that emerged after the Spanish Civil War, which looked up at the tenets of international modernism, while resorting to vernacular traditions in order to find its own profile. The Casa de Campo fair grounds, raised on the verge of Madrid in a time of scarcity, provided several sites where terraces were needed to allocate an exhibition program, transferring a characteristic feature of the rural landscape onto the urban periphery. This paper explores the different ways in which the Hexagon pavilion (1958-1959), the Ministerio de la Vivienda pavilion (1959) and the Bancadas pavilion (1962-1965) hosted an exhibition program and adapted to the sloping terrain by means of petrous, stereotomic structures linked to the ground and light, tectonic frames linked to their roofs.

$\mathrm{D}$ esde los Arribes del Duero hasta la Sierra de Tramuntana, los bancales protagonizan buena parte de la geografía española. Estas mesetas de tierra construidas entre muros paralelos a las curvas de nivel han habilitado tradicionalmente las laderas para el cultivo incrementando las tasas de infiltración y reduciendo los procesos erosivos (Lasanta 2013: 301). Asimismo, también han proporcionado una forma de habitar la pendiente que reduce las grandes excavaciones y desmontes, a la vez que propone configuraciones espaciales que le son propias. En España, la economía de medios que se impuso tras la Guerra Civil, junto con la creciente sensibilidad hacia el paisaje y las tradiciones vernáculas, hizo que estas construcciones en terraza proliferaran en las décadas siguientes al fin del conflicto, dando lugar a un catálogo diverso de soluciones que merece una mirada atenta. Este artículo se propone estudiar dichas respuestas a un emplazamiento inclinado, centrando este análisis en tres pabellones que formaron parte de la Feria del Campo de Madrid: el pabellón de Hexágonos (1958-1959), la edificación de Bruselas y su adaptación para su ubicación madrileña, el pabellón del Ministerio de la Vivienda (1959) y el pabellón de Bancadas (1962-1965). Este conjunto de construcciones expositivas se integraba en el plan de ordenación propuesto por Francisco de Asís Cabrero y Jaime Ruiz para la II Feria Internacional del Campo celebrada en 1953 que ampliaba hacia el oeste con un nuevo trazado el recinto original de la primera Feria Nacional ("La Feria del Campo"
1951) hacia el oeste y proponía un repertorio de estrategias proyectuales para habitar el bancal y apropiarse del mismo como una suerte de paisaje expositivo interior.

\section{Una cuña de campo que se introduce en la ciudad}

Situada sobre la loma que asciende hacia el oeste desde la margen occidental del río Manzanares, la I Feria Nacional del Campo ${ }^{1}$ ocupaba los terrenos entre la nueva carretera de Extremadura y el lago de la Casa de Campo y fue inaugurada el 27 de mayo de 1950, recuperando la tradición de las primeras exhibiciones que la Asociación de Ganaderos del Reino ${ }^{2}$ había venido celebrando alli entre 1923 y 1930 hasta la caída de la monarquía de Alfonso XIII con el advenimiento de la República el 14 de abril de 1931. El éxito de la primera convocatoria tras la Guerra Civil, en la fase final del periodo autárquico, constaba de 42 construcciones sobre 15 hectáreas y dio pronto paso a una nueva versión del certamen en 1953, ahora internacional ${ }^{3}$, que amplió sus instalaciones a unas 70 hectáreas. Esta segunda feria fue modesta en cuanto a representación extranjera, participando sólo Portugal y Argentina con la construcción del pabellón Internacional, llegando en su evolución posterior a acoger más de un centenar de construcciones ${ }^{4}$ que incluian las representaciones de las Cámaras Agrarias regionales y los pabellones de Argentina, Alemania, Portugal o Estados Unidos, entre otras sedes. El recinto ampliado -que acabaría por acoger 
nueve convocatorias más entre 1953 y 1975 fue definido como "una cuña de campo que se introduce en la ciudad" ("La Feria del Campo" 1951: 22) y su ordenación estuvo igualmente a cargo de Cabrero y Ruiz. Apoyándose en la configuración natural del terreno, la urbanización se estructuraba a partir de una vía sinuosa que recorría el recinto de este a oeste, vinculando la circunvalación del ferial inicial con un remate en "S" que definía el palacio de la Agricultura y la pista grande de exhibiciones incorporando las dos colinas situadas en la parte occidental de la nueva parcela. Cruzando en diagonal el conjunto, la calle del Ángel dibujaba la cesura entre las dos fases de la Feria.

En la perspectiva dibujada por Cabrero en 1952 (figura 1), la ampliación aparecía dominada por dos grandes piezas: una torre que se elevaba por encima de los árboles y un pabellón de doble curvatura que abrazaba el graderío de la pista de exhibiciones, instalada en una vaguada entre ambas colinas. Este nuevo centro se elevaba unos cuarenta metros sobre la torre restaurante, remate de la primera Feria, convirtiéndolo igualmente en un mirador natural sobre la sierra y la cornisa histórica. El acusado relieve de la ampliación en los flancos de ambos cerros, junto con el hecho de que la zona aún presentaba las trincheras de la guerra, proporcionaron unas condiciones de partida para la construcción de pabellones que no fueron tan homogéneas como en la primera fase ${ }^{5}$. En el documental Nuevos Cimientos (1953) se muestra el movimiento de tierras necesario, rellenando minas $\mathrm{y}$ trincheras, en un entorno con constantes cambios de cota (figura 2).

Esta primera actuación fue ampliada con otra importante operación de contención y explanación mediante bancales realizada para la tercera Feria en 1956 y completada en una segunda fase en 1957. Consistió en la preparación de la zona de exhibición de maquinaria al aire libre ${ }^{6}$ mediante un gran muro de contención que salvaba un desnivel de $6 \mathrm{~m}$, ampliando la superficie de exposición mediante otros muros de menor altura que definian plataformas sucesivas. El sistema de terrazas llegaba hacia el norte hasta la ronda del Lago, extendiéndose en longitud hacia el este, englobando a los pabellones del INI, Argentina y hasta el pabellón de Bancadas. La superficie de exposición conseguida era de unos $25.000 \mathrm{~m} 2$, lo que suponía un gran activo para la Feria tal y como puede verse en las fotografias aéreas. El muro principal que aún se conserva -aunque es urgente su

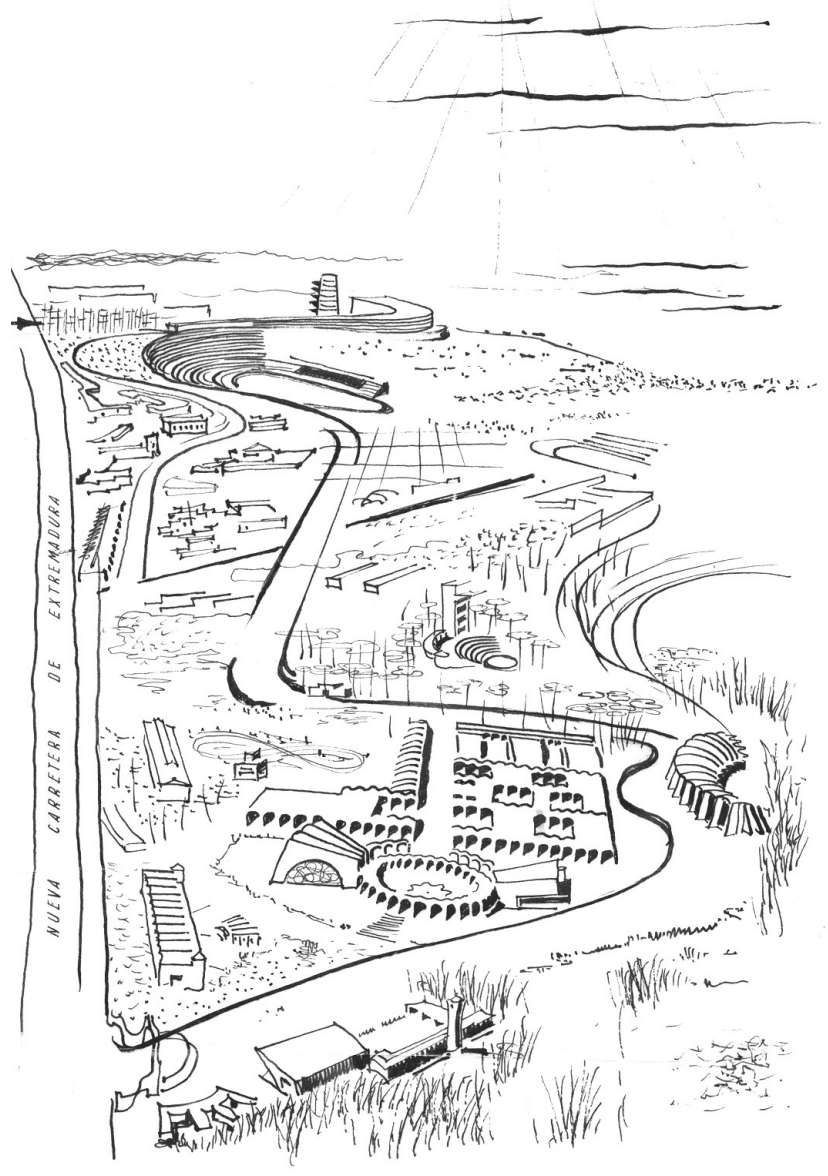

restauración- está realizado con mampostería granítica irregular aparejada "en seco", es decir, sin relleno de mortero en sus juntas, al menos en su cara exterior. Su sistema constructivo probablemente se inspire en el modelo romano "por gravedad", con una gran base que va reduciendo su espesor por tramos horizontales a medida que aumenta su altura. Es impresionante su aspecto sólido como basamento constructivo y visual de los edificios representativos del "ágora expositivo" (Coca 2013: 242): los pabellones de la Pipa y el de Cristal y su carácter de atalaya ya que desde su parte superior se domina el

Figura 1. Ampliación de la Feria del Campo. Croquis de Francisco de Asís Cabrero. (La Feria del Campo 1951: 170).

Figura 2. Anteproyecto II Feria Internacional del Campo. "Proyecto de explanación de trincheras en la Feria Nacional del Campo", marzo 1952. Arch. General de la Administración, Fondo Sindicatos Top $34 \mathrm{C} 486$.

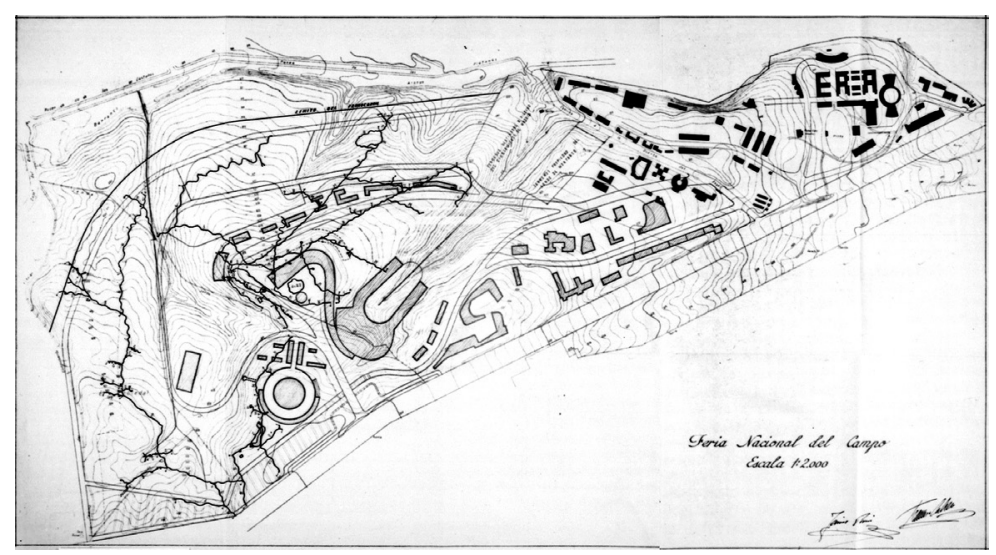


Figura 3. Francisco Proyecto de muros de contención en bancales de maquinaria, diciembre 1955. Planta general, E: 1/500. AGA Sindicatos Top 34, C471.

Figura 4. Vista aérea de la explanada de maquinaria (fragmento). Archivo Familia Cabrero. Cabrero y Jaime Ruiz:

arco de vistas desde la sierra hasta la cornisa histórica (figuras 3 y 4). Así, las acusadas pendientes de ciertas parcelas obligaron a los arquitectos a recurrir a una técnica de origen agrícola como es el bancal para poder implantar los pabellones sobre las superficies horizontales proporcionadas por las terrazas. Este es el caso del pabellón del Ministerio de la Vivienda, del pabellón de Bancadas o del pabellón de Hexágonos que a continuación se analizan.

\section{El pabellón del Ministerio de la Vivienda (1959)}

Una vez realizado el trazado de ampliación de la Feria, Francisco Cabrero y Jaime Ruiz llevaron a cabo los pabellones de la Organización Sindical y de los organismos de la vivienda: la Obra Sindical del Hogar y el Ministerio de la Vivienda. Este último, realizado en 1959 para la IV Feria Internacional, aunó la lógica constructiva con un novedoso espacio expositivo, fruto en gran medida de
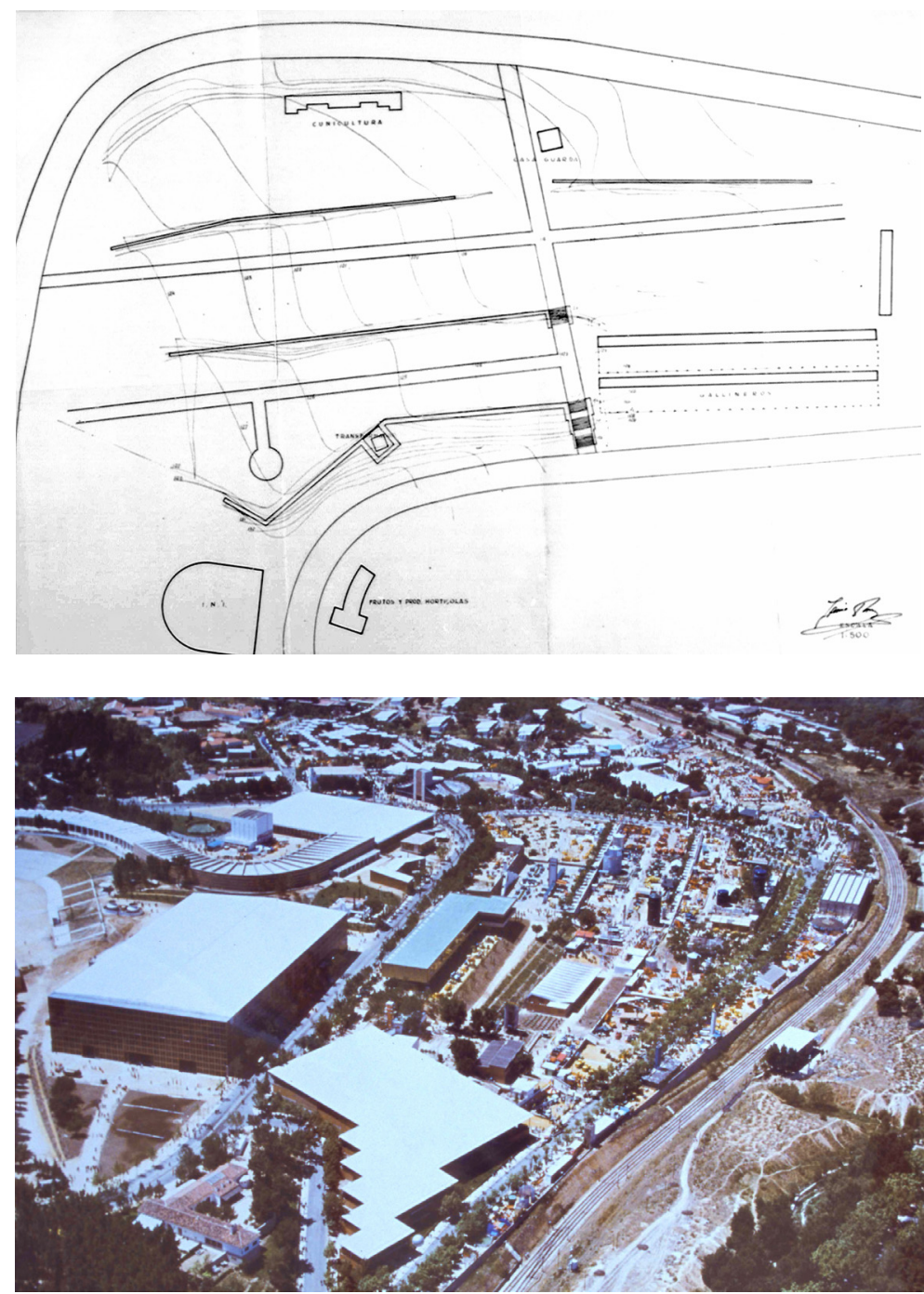

su adaptación a un solar en pendiente a base de bancales.

El proyecto inicial ${ }^{7}$ fue concebido para una parcela situada en el paseo del Ángel, al lado del pabellón de Pontevedra de Alejandro de la Sota. Este anteproyecto (figura 5) conservado en el legado Cabrero, consistía en un espacio unitario con una altura de $5 \mathrm{~m}$, y una planta de 15 × 30 m formando un doble cuadrado. Estaba definido por dos muros en forma de "L", uno de ladrillo que lo envolvía y aislaba de la calle y el otro creando un patio, interiormente otro formado por una retícula de vidrios definía la sala. 10 semipórticos, otra vez en forma de "L", sujetaban la cubierta con ménsulas hacia el ventanal y apoyados en el muro visto.

La perspectiva interior muestra un espacio expositivo dinámico que fuga continuando el lateral derecho hacia el muro situado al fondo y es iluminado por el lado izquierdo, expresando simultáneamente frontalidad y lateralidad, potenciadas por el vidrio, las bandas estructurales y la luz horizontal del patio. En este primer anteproyecto se rescataban soluciones ensayadas en el pabellón de la Obra Sindical del Hogar (OSH) -realizado en 1956 por Francisco Cabrero y Felipe Pérez Enciso ("III Feria del Campo, Madrid" 1956: 51-55)- pero sobre todo, la mezcla del espacio dinámico y fluido del pabellón de Barcelona con otro tipo espacial basado en el espacio flexible y unitario de la obra americana de Mies van der Rohe. Estas operaciones de transformación espacial se pueden también considerar como una evolución de otros espacios unitarios, es decir, las grandes salas diáfanas que obsesionaban a Cabrero ensayadas con el pequeño prototipo de la capilla en la Feria y su desarrollo en el proyecto realizado con Aburto para el Concurso de la Catedral de Madrid (Coca 2013: 189-195).

El cambio de emplazamiento obligó a transformar la solución inicial (Cabrero y Ruiz 1959: 16-19). Situada en la Cuesta Nueva -frente al pabellón de los Hexágonos y detrás de la plaza de Toros y el pabellón de Valencia, la nueva parcela era un solar alargado y elevado respecto a la calle, con un importante desnivel de $8 \mathrm{~m}$ y las curvas de nivel en diagonal, lo que impedía la colocación del prisma original. El nuevo edificio (Cabrero y Ruiz 1959: 16-19) se dividió así en tres naves y media, escalonadas en planta según la dirección de la calle y en diagonal a las curvas de nivel y por bancales en sección. Esta solución aprovechaba estos factores adversos, perfeccionando la primera versión. La nave 


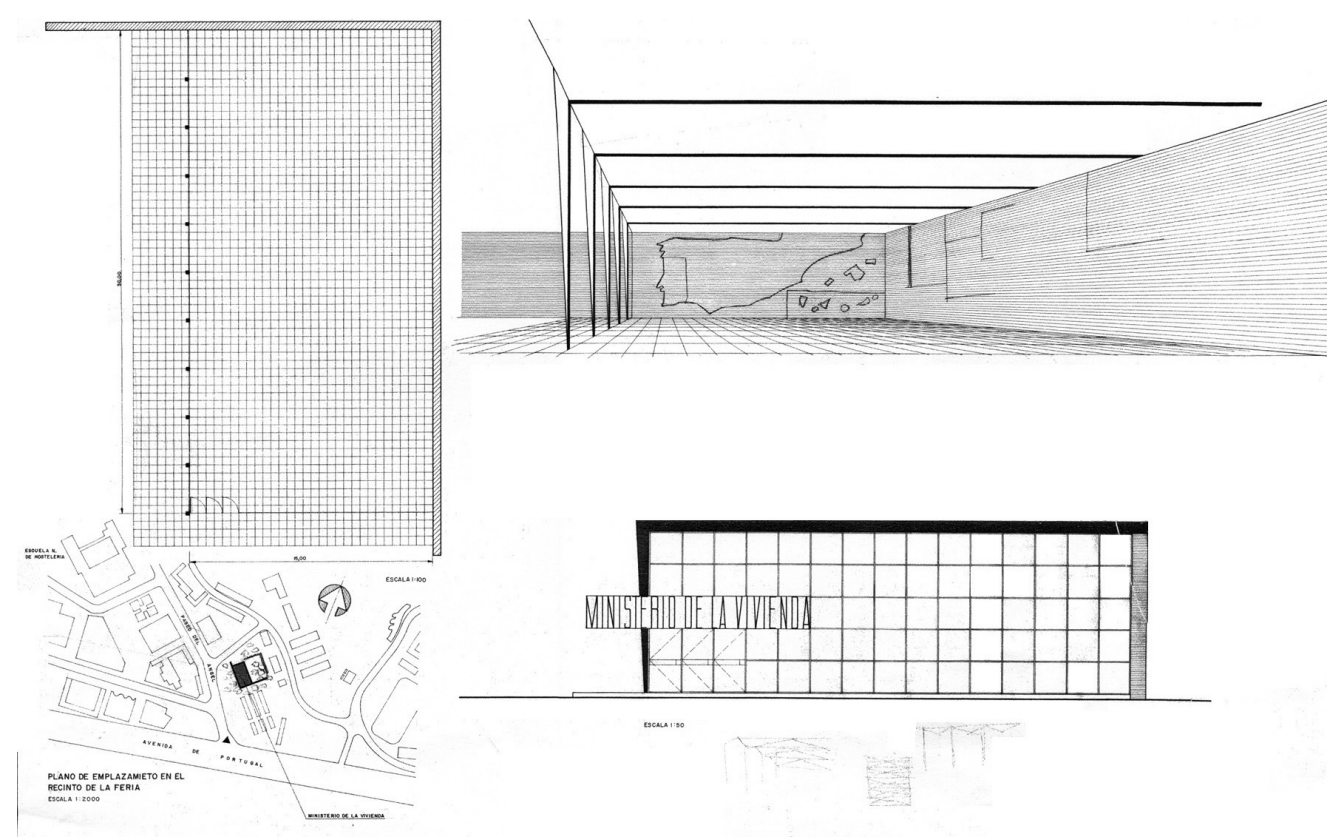

tipo pasó a ser entonces otro doble cuadrado de 11 x $22 \mathrm{~m}$ con una altura de $5 \mathrm{~m}$. Consiste en un pabellón independiente cubierto con dos vigas longitudinales de $50 \mathrm{~cm}$ de canto y 31 viguetas perpendiculares de $24 \mathrm{~cm}$. Las vigas se sujetan en las esquinas por pilares dispuestos a cada lado de la viga según queden libres o adosados al siguiente pabellón. Los prismas se desfasan paralelos a las curvas de nivel y siguiendo la diagonal del cuadrado formando una retícula de 11 x $11 \mathrm{~m}$, resultando que el pilar en esquina de una nave es el central del vano de la siguiente. Se forma asî una ingeniosa retícula estructural, o visto de otro modo, una secuencia de pórticos de 1, 2 o 3 vanos, desplazados $11 \mathrm{~m}$. Cada nave-sala tiene un vano de $11 \mathrm{~m}$ común con la siguiente, produciéndose un espacio tensado en diagonal -tanto en planta como en altura- que las atraviesa, uniendo el conjunto mediante el espacio oblicuo resultante, que es el protagonista del edificio (figura 6).

Los arquitectos aunaron así, mediante los pórticos desplazados en horizontal, el espacio estratificado consistente en pantallas sucesivas de arcos, como ocurre en la mezquita de Córdoba, características del espacio interior hispano-musulmán, y la fuga visual propia del espacio focalizado cristiano tal y como indicaba Chueca Goitia (1971), resultando una solución moderna a partir de los dos tipos espaciales característicos de oriente y occidente. El objetivo último sería reforzar y no interferir en este espacio unitario diagonal (figura 7). Apoyando esta idea espacial, cada nave se cierra con el diedro de ladrillo y vidrio ya planteados en el anteproyecto, en una con- figuración que solo se interrumpe con el vacio diagonal y la fuga visual, manteniendo la característica espacial de frontalidad y lateralidad del primer proyecto, creando un espacio estratificado y continuo definido por la trama de las viguetas del techo y de efecto telescópico por el escalonamiento en planta y sección.

Los sucesivos retranqueos de la planta se adaptaban así al contorno de la calle, mientras los escalonamientos en sección acomodaban progresivamente el edificio al terreno. Por tanto, los desniveles interiores no son homogéneos, siendo de $2 \mathrm{~m}$ en la primera bancada, $1 \mathrm{~m}$ en la siguiente y $0,5 \mathrm{~m}$ en la última, conservándose los $5 \mathrm{~m}$ de altura en cada nave. Estos cambios de cota se manifiestan en la cubierta y son utilizados para introducir luz natural, como ya hizo Frank Lloyd Wright en las casas Usonianas (McCarter 2007: 248-271). El planteamiento constructivo es, sin embargo, deudor de la admiración de sus autores por la obra de Mies en el Campus del IIT; una influencia que ya fue mencionada por Cabrero al explicar el edificio en 1986 (Mata y Sobejano 1987: 110-115):

... me llamó la atención la obra de Mies en el año 1954 cuando viajé a América. No lo conoci personalmente, pero si visité sus edificios, estuve en el IIT. Me interesó su obra de origen neoplasticista. En realidad los rascacielos de Chicago no eran lo mejor.

La geometría de líneas y planos que definía la estructura y el cerramiento no fue la única referencia "miesiana" en el proyecto. Dada la proximidad programática, el espacio fluido del pabellón de Barcelona -que Cabre-
Figura 5. Derecha. Francisco Cabrero y Jaime Ruiz: Anteproyecto del pabellón del Ministerio de la Vivienda, 1959. Legado Cabrero Fundación COAM. 


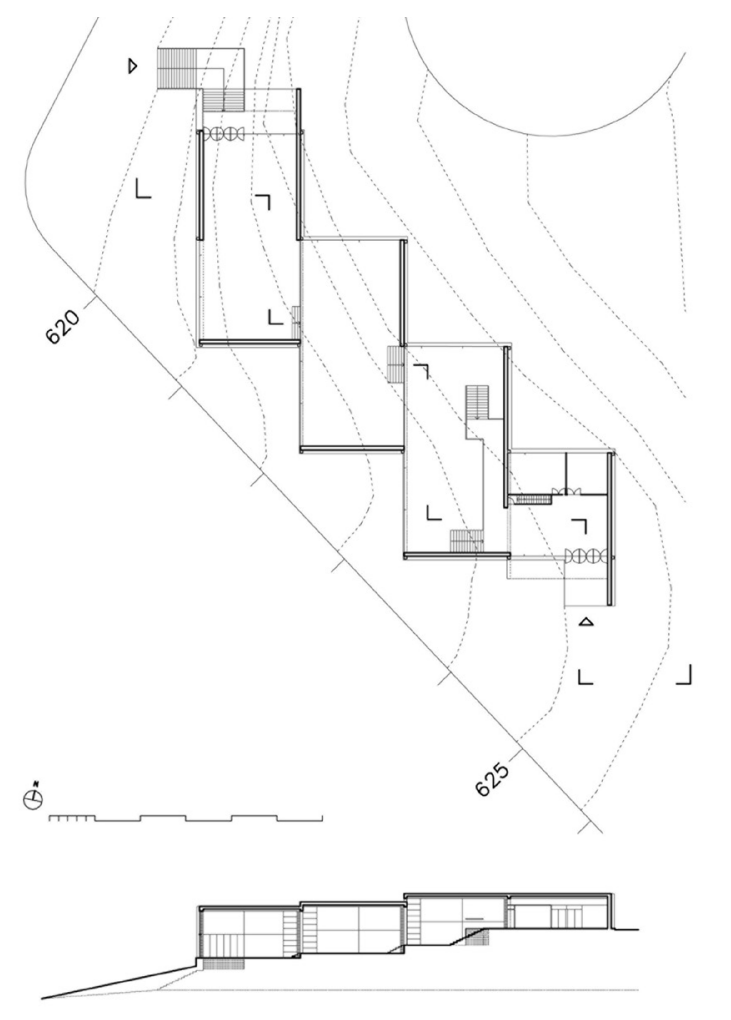

Figura 6. Francisco Cabrero y Jaime Ruiz: pabellón del Ministerio de la Vivienda 1959 Planta, sección y topografía. Dibujo del autor.

Figura 7. Interior oblicuo, pabellón del Ministerio de la Vivienda. 1959. Archivo Familia Cabrero. ro admiraba por el contraste entre el carácter clásico y el vernáculo- servirá de inspiración al "tubo expositivo" (Coca 2013: 321) del pabellón madrileño. Como Cabrero señala en el Libro III (Cabrero 1992: 359):

Este edificio se reducia, en cuanto a programa, a la más simple solución: un único ambiente abierto y techado en dos zonas -la propiamente de exposición y la de servicio, apoyada en la fábrica de reparto-, cuidado basamento, ricos cerramientos revestidos por diferentes mármoles y ordenada planta según el más puro sentido vandoesburgués.

En el pabellón de Cabrero y Ruiz, los pilares desaparecian en el interior y el peso del ladrillo contrastaba con la ligereza del vidrio con diferentes efectos de luz según la orientación. La iluminación natural estaba regulada mediante estores tipo "gradulux" reflejándose en la estructura del techo lo que recorda-

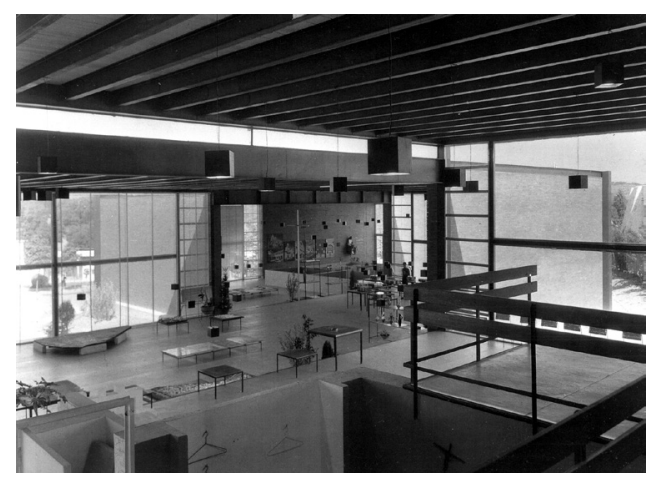

ba a un interior japonés que adquiría una cualidad infinita gracias al espacio diagonal continuo y los planos múltiples de ladrillo y vidrio. El recorrido atravesando en diagonal o bordeando las salas también contribuía a este efecto de multiplicidad y ligereza que se potenciaba con las mesas de cuadradillo de acero y madera que repetían la idea estructural y las lámparas cúbicas que flotaban a distinta altura. Los prismas escalonados, tienen algo del efecto masivo y a la vez ligero del monumento a Karl Liebknecht y Rosa Luxenburgo hecho por Mies en 1926, o la diafanidad y multiplicidad del palacio de Katsura, ambos representados en los cuatro libros. El pabellón era, por tanto, otro "Tubo expositivo"-un espacio expositivo unitario, delimitado por dos muros laterales y con dos extremos libres-, que fue un tema ampliamente explorado en la feria, como un canal espacial que conducía a la masa de visitantes entre dos entradas simétricas, enfatizadas con las viseras de entrada y salida.

\section{El pabellón de los Hexágonos (1958-1959)}

Frente al Pabellón de la Vivienda, en un solar de similares características, se sitúa el llamado pabellón de los Hexágonos ("La arquitectura de la Feria del Campo" 1959: 8689). En abril de 1959 se trasladó y reinstaló en Madrid el pabellón que representó a España y había obtenido un enorme éxito en la Exposición Universal de Bruselas. En la capital belga, el edificio debía ceñirse a un solar de traza triangular y bordes curvos, abrazar una colina de $6 \mathrm{~m}$ situada en una posición central y respetar el arbolado del parque en el que se insertaba. Ante una topografía que caía en direcciones diversas, los arquitectos idearon una pieza de cubierta ligera y desmontable, de geometría hexagonal, que por repetición generaba la planta.

Esta discretización de la cubierta en elementos autónomos en cuanto a sistema estructural y de evacuación del agua permitía adaptarse a los cambios de rasante con una enorme flexibilidad. Para hacer habitable la falda de la colina, se banqueó el solar siguiendo la trama hexagonal de la cubierta, aprovechando las distintas alturas de los paraguas hexagonales para dejar pasar la luz. El cerramiento perimetral acristalado introducía al interior las vistas de los árboles, desdibujando el limite entre el interior y el exterior. Se configuró así un paisaje expositivo continuo de paredes listonadas como biombos que acogía una exposición minimalista de objetos-motivo con vitrinas hexagonales de $2 \mathrm{~m}$ 


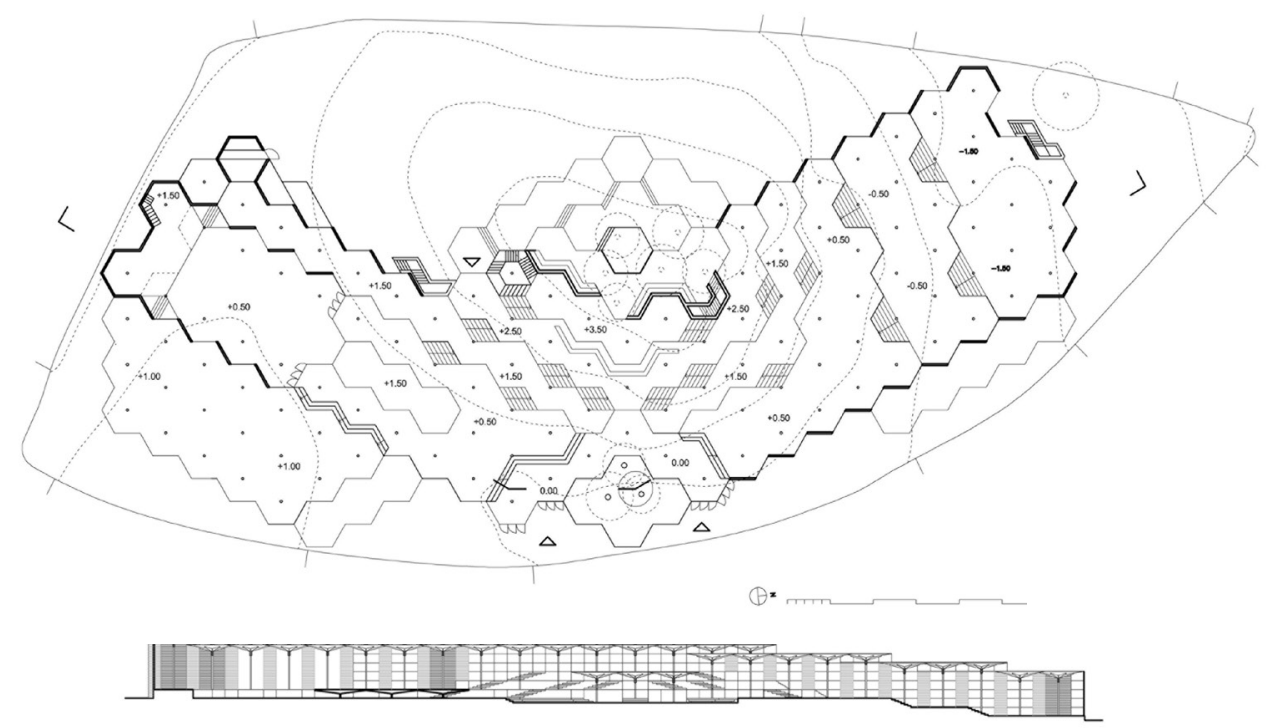

de diámetro colocadas a distintas alturas, siguiendo los vértices de la red establecida por la cubierta ("El pabellón de España" 1958: 1-10). El vacío debía ser el protagonista, con pocos objetos, según recordaban J.A. Corrales y Joaquín Vaquero una de las ideas utópicas sería que el público pasease escuchando versos de Juan Ramón Jiménez y música de Manuel de Falla. Los bancales de traza hexagonal -ligados a la tierra por su materialidad cerámica- eran por tanto los que articulaban ese paisaje expositivo sembrado al tresbolillo con los paraguas -metálicos y ligeros, ligados al aire- que prolongaban al interior el bosque circundante (figuras 8 y 9).

La instalación en Bruselas no estuvo exenta de dificultades, incluyendo retrasos por huelgas y lluvias y, sobre todo, por la polémica suscitada por el programa expositivo propuesto (Corrales 2005: 21-46). Pese a todo, los arquitectos Corrales y Molezún recibieron una carta del Comisario de la exposición española, Miguel García de Sáez, consultándoles sobre posibles emplazamientos una vez concluida la muestra, invitándoles a supervisar el desmontaje y realizar un nuevo proyecto. La carta sugería un pabellón en el parque del Retiro o un edificio de recepción en el aeropuerto. Conscientes de la limitada utilidad del pabellón por la poca separación de las columnas, inadecuado para objetos grandes, les agradaba la opción de un club-ateneo en la Ciudad Universitaria, manteniendo la versión de Bruselas, refrendaban la opción del Retiro y veían muy buena una terminal: "tal vez sería la idea más espectacular dado el gran tránsito aéreo de viajeros, además de una bonita entrada a Madrid", una vez encontrado un solar con una topografía similar a la del parque Heysel, lo que no dejaba de ser bastante forzado. El material recuperado finalmente fue entregado a la Delegación Nacional de Sindicatos, fijándose en la ampliación de la Feria del Campo un solar de naturaleza muy diferente a Bruselas atravesado por una vaguada, casi triangular, con $6 \mathrm{~m}$ de desnivel y numerosas encinas. Corrales y Molezún rodearon los hexágonos con muros de ladrillo para protegerse del poniente y las vistas indeseadas, organizando tres patios alrededor del arbolado: uno cerrado en la entrada, y dos en la parte baja, acristalados hacia la sierra. Al otro lado, el pabellón del Ministerio de la Vivienda descrito anteriormente. Entre ambos edificios, de materiales similares y adaptados a la topografia mediante aterrazamientos de un metro de altura, surge una interesante relación: el agregado hexagonal dialoga con la claridad y la potencia visual de los prismas-sala (figuras 10 y 11).

Del pabellón de Bruselas se recuperaron 130 paraguas de 2,95 $\mathrm{m}$ de lado y alturas

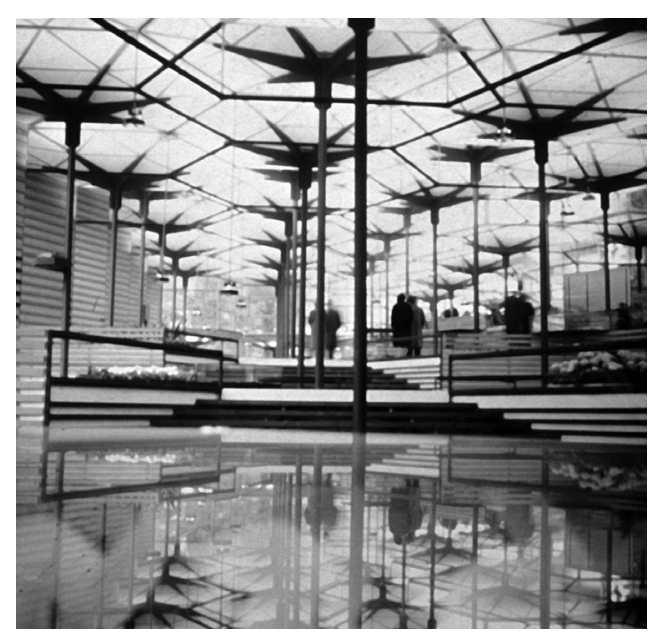

Figura 8. José Antonio Corrales y Ramón Vázquez Molezún: pabellón de Bruselas. Planta, sección y topografía de la versión realmente construida. Dibujo del autor.
Figura 9. Paisaje interior abancalado del pabellón de Bruselas, 1958. (Cánovas y Corrales 2005: 177). 
Figura 10. Paisaje interior en la instalación de la Casa de Campo, 1959 (Cánovas y Corrales 2005: 191).

Figura 11. José Antonio Corrales y Ramón Vazquez Molezún: pabellón de Bruselas en la Casa de Campo. Planta, sección y topografía de la versión construida incluido en proyecto de ampliación de 1968. Dibujo del autor.

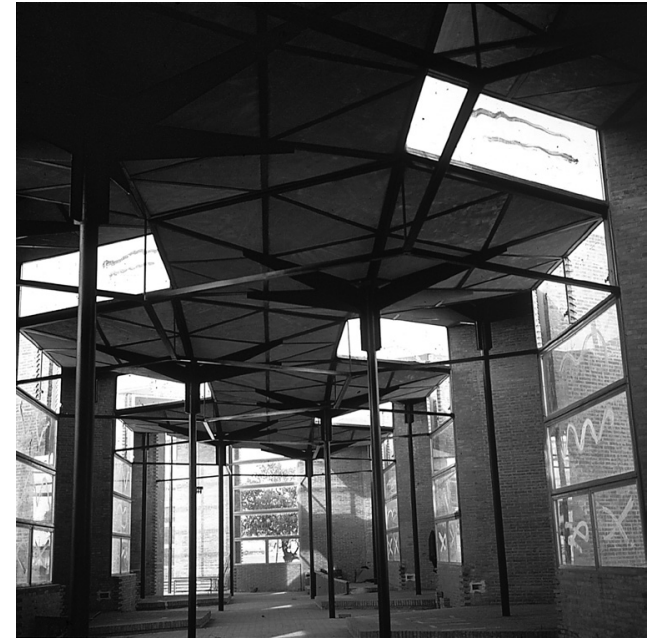

entre 3,50 m y 9,25 m, además de, 12 invertidos, 527 ventanas, tubos de unión, luminarias hexagonales, calefactores y focos. La nueva instalación, con algo más de $3000 \mathrm{~m} 2$, correspondía a 131 hexágonos, realizándose pocas modificaciones: acortando y adaptando los pilares y reutilizando todos los paraguas invertidos. En las entrevistas, Corrales afirmaba entusiasta:

Lo bonito de este pabellón es que es tan flexible... Tengo tantas piezas y tengo que utilizarlas, y puedes montarlo de mil maneras. ${ }^{9}$

La lógica compositiva y la exploración de posibilidades llevó a generar unas salas alargadas y menos flexibles, un crecimiento en "mancha" de células hexagonales, alrededor de vacíos intersticiales. Se trataba de un

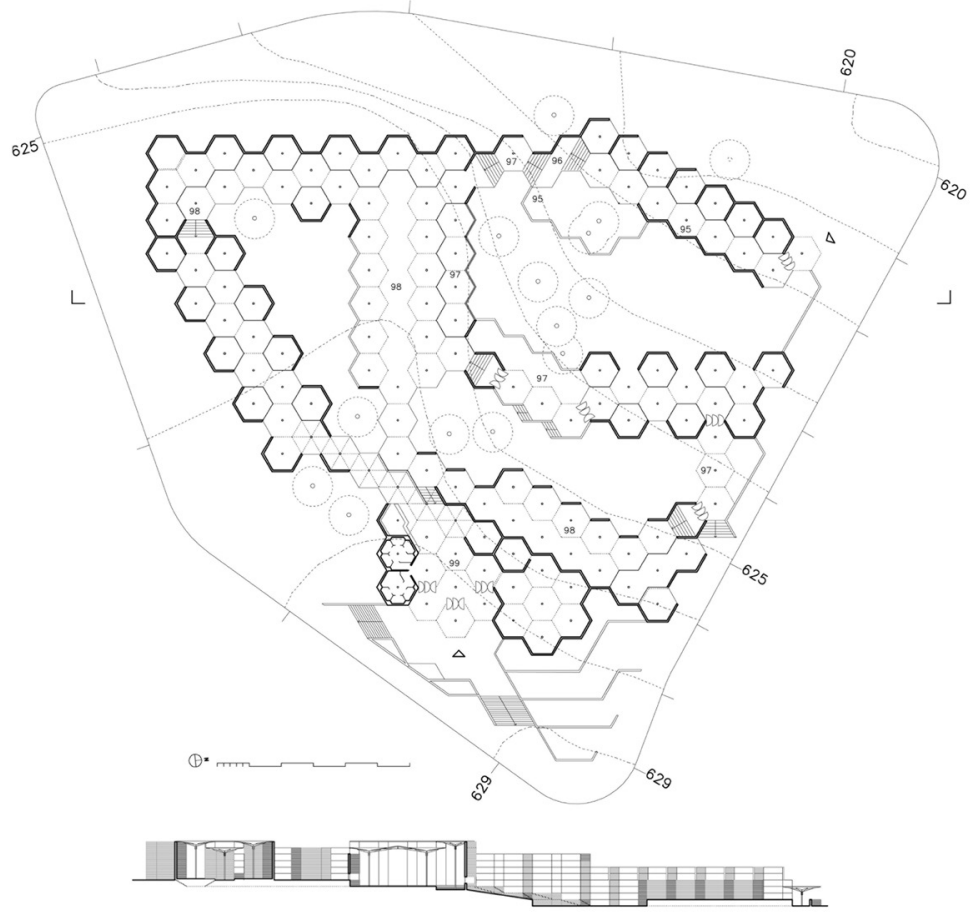

esquema orgánico pero funcionalmente más rígido y muy diferente a la compacta "V" de Bruselas, donde dominaba la fluidez y flexibilidad a pesar de las mesas expositivas hexagonales fijas. En la Feria, se diferenció entre hexágonos de circulación y hexágonos de exposición, elevando el pavimento. Todo quedó sometido a la ley hexagonal, incluidos los patios, encajándose la malla de $3 \mathrm{~m}$ con las alineaciones y los vértices del solar. Como en Bruselas, las salas se adaptaron mediante banqueos de $1 \mathrm{~m}$. Los recorridos se configuraron zigzagueantes o continuos, según la colocación de los hexágonos de circulación y exposición, obteniendo crujías de tres elementos. El desfase de las cubiertas, también en saltos de $1 \mathrm{~m}$, con la luz incidente según el lado abierto, su relación con los muros de ladrillo y el recorrido del visitante, actuaban como mecanismos de diferenciación espacial, como comentaba Corrales:

...las obras son sistemas de estructura... Pero si lo sigues al pie de la letra, hasta el final, acabas aburrido y es muy pesado. Las obras requieren en un momento dado romper. Lo que pasa es que hay que saber romper, esa es la dificultad que tiene introducir un elemento nuevo que te sorprenda... ${ }^{10}$

La entrada es un atrio con 6 columnas alineadas, de $8 \mathrm{~m}$ de altura, formando unos cuerpos hexagonales de vidrio. Visible desde todos los puntos, el punto de comienzo y finalización del recorrido, comunicando directamente con la sala de actos, situada en la conjunción de los tres patios con acceso a cada lado del escenario. Como en Bruselas, el eje de la sala, son seis elementos invertidos formando pórticos de $9 \mathrm{~m}$ apoyados en dos filas de paraguas. El resto de elementos invertidos se utilizaron para cubrir las escaleras sobre los muros. La permeabilidad visual entre patios se logró con tres paraguas sin cerramiento; un recurso también empleado en la entrada acristalada y en las salidas de los patios. Se aportaron nuevas soluciones, como las ventanas en contacto con el terreno, a media altura al interior, provocando al visitante la sensación de sumergirse en el terreno. La variedad de situaciones no logró, a pesar de los patios, crear el orden espacial necesario, provocando una sensación laberíntica. En Bruselas dominaban las fugas visuales, la ligereza y la irrealidad: provocada por la luz entre los paraguas grises, los tímpanos blancos, los biombos-cerramiento listonados, el pavimento triangular de barro y las livianas escaleras de madera, produciendo la impresión de pa- 
sear por una colina arbolada. En Madrid, el carácter duro del ladrillo a soga trabando las esquinas y a sardinel en suelos y escaleras contrastaba con las columnas hexagonales y las superficies de vidrio. Los paraguas cerrados en dos o tres caras se mostraban como torreones; la visión, buscada por los autores, de una fortaleza castellana o una nave gótica alternaba con el carácter de mezquita, o gran sala hipóstila. Además, la malla adaptada al movimiento, con interior y exterior iguales, junto al carácter de construcción nacida del terreno, evocaban las casas usonianas y las columnas del edificio Johnson Wax de Frank Lloyd Wright que seguro inspiraron la solución del paraguas hexagonal, igualmente autónomo estructuralmente y en cuanto a la evacuación de agua.

En junio de 1967, ocho años después, el pabellón de Bruselas, según José Luis Fernández del Amo, está: "mal reconocido y mal conservado" (Fernández del Amo 1969: 62). Como arquitecto del Ministerio de Agricultura, interviene en la permuta con la Obra Sindical, hasta ese momento responsable del pabellón de Bruselas, por el pabellón del Ministerio de Agricultura del arquitecto Carlos Arniches, situado en la entrada de la parte antigua. Corrales y Vázquez Molezún trabajan en la reforma y reparación, ampliando la zona de entrada con 13 hexágonos, creando un vestíbulo con mostrador, dos nuevos aseos y una sala de recepción en forma de tambor. Es un espacio hipóstilo con seis paraguas, de $7 \mathrm{~m}$ de altura, rodeando a uno central, dos metros más bajo, por el que entra la luz, resultando un espacio recogido e íntimo que evoca a una capilla medieval. Desde 1975, a pesar del cambio de organismo, el pabellón cayó otra vez en desuso con la desaparición de las Ferias y la creación del Patronato de la Feria del Campo deteriorándose rápidamente. Corrales y Vázquez Molezún realizaron en 1991 un nuevo proyecto ${ }^{11}$ de reconstrucción y aprovechamiento (figura 12):

... nos llamaron del Ayuntamiento. Era una solución para la mitad del pabellón, y consistia en dejarlo sin cerramientos como un porche, para paseos con flores, un jardin bien puesto; y la otra mitad, dividirlo. Uno, hacer un restaurante con una cocina y otra pequeña construcción $y$, otro, un centro cultural de barrio. Se construía una especie de cubierta adosada al pabellón, una cubierta ligera, plana, de chapa de aluminio... ${ }^{12}$

La desaparición de los vidrios y bastidores, el deterioro estructural y por humedad

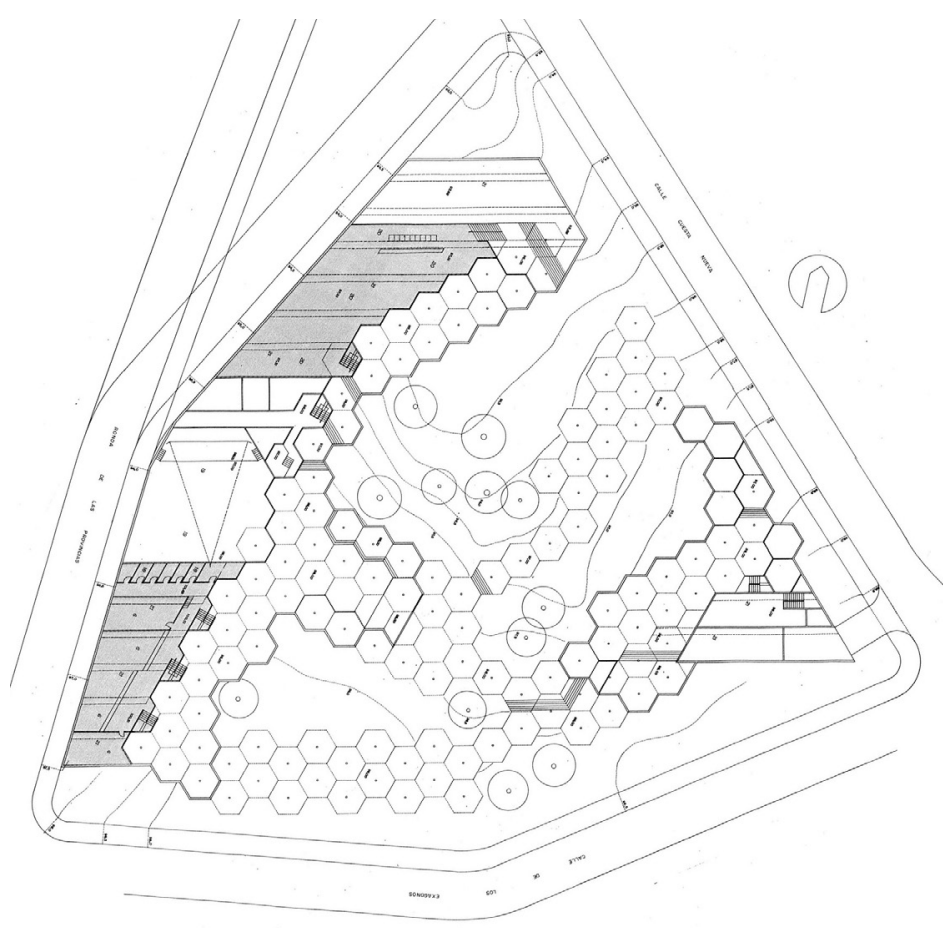

de los muros, y su dificultad para la organización de exposiciones, aconsejó dejar los paraguas sin cerramiento. Fue un intento de recuperar la espacialidad del pabellón original, trasladando el programa a un contenedor convencional. Vázquez Molezún no era partidario, según indicaba Corrales, inventor de la nueva solución. La ampliación al oeste se adaptaba al contorno original, orientando las naves y lucernarios en la dirección este-oeste iluminando la biblioteca, el salón de actos y los talleres que se volvian a adaptar a la topografia formando terrazas en continuidad con las antiguas. Las dos naves alargadas de dos y tres hexágonos y la sala de actos original se cerraron con la nueva fachada; en la zona central quedaron los paraguas exentos y en el extremo este el pequeño bar-restaurante maclado siguiendo la orientación de las naves. Grandes bandas horizontales de aluminio formaban la fachada que también se adaptaba a los bancales.

\section{El pabellón de las Bancadas (1962-1965)}

Unos años más tarde, una nueva variante de adaptación a la pendiente se plantearía en el recinto ferial con el pabellón de las Bancadas. Para la V Feria Internacional, en 1962, se construye un pabellón de exposiciones en el que Cabrero y Ruiz vuelven a resolver ventajosamente una topografia y un solar complicados. El edificio, ampliado en 1965 para la IV Feria Internacional, se situaba frente al actual pabellón de Cristal en una parcela en
Figura 12. José Antonio Corrales y Ramón Vázquez Molezún: proyecto de reforma del pabellón de Bruselas para biblioteca y centro cultural, 1991. Archivo Corrales. 


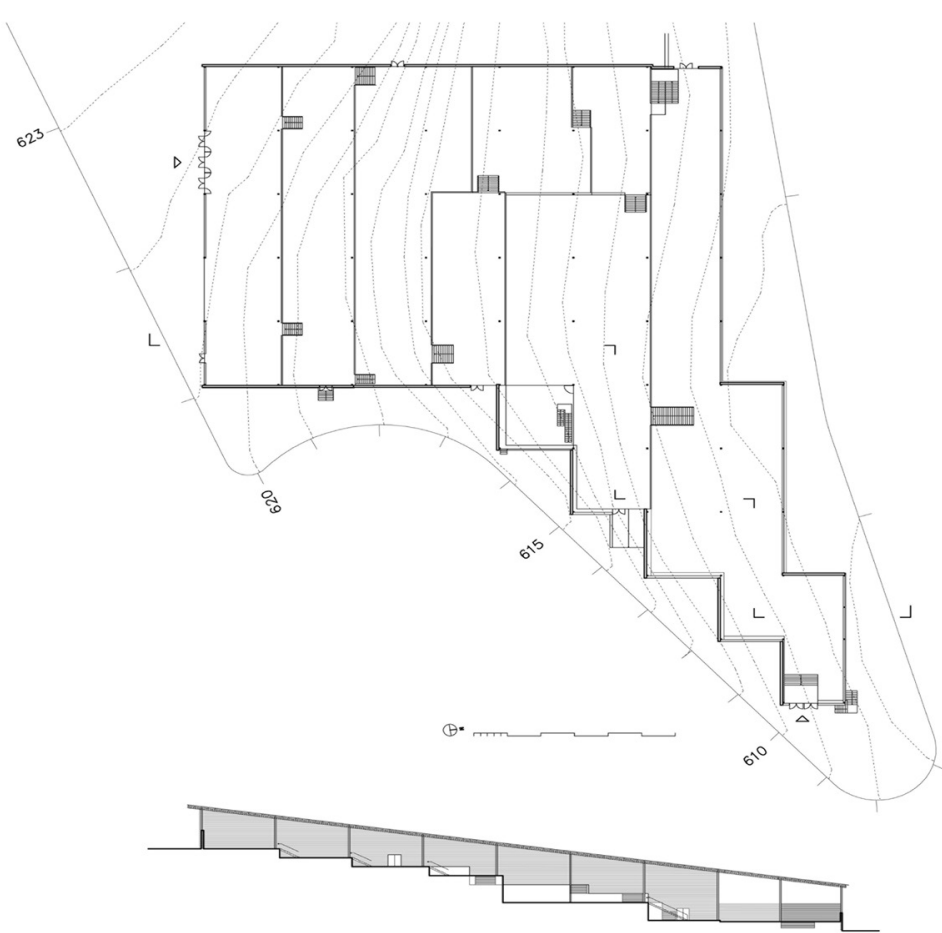

Figura 13. Francisco Cabrero y Jaime Ruiz: pabellón de las Bancadas. Planta, sección y topografía. Dibujo del autor.

Figura 14. Paisaje interior del pabellón de las Bancadas, 196265. Memoria de la VII Feria Internacional del Campo, 1968. cuña con un fortísimo desnivel de $14 \mathrm{~m}$, resolviendo la adaptación entre la prolongación del muro de maquinaria, la curva de la Cuesta del Arroz y la ronda del Lago lindando con el ferrocarril (figura 13).

Sin un programa expositivo concreto, fue la primera construcción que definió la nueva calle del Ferial, al norte de las terrazas y el muro de contención de la exposición de maquinaria al aire libre. La solución se basó en una anterior, el pabellón de las columnas realizado para la III Feria Internacional en 1956. Una gran sala hipóstila sin cerramiento y con pórticos en la dirección este-oeste, cerrando la plaza con el Cubo y la Pipa. El nuevo pabellón del Lago, llamado también "de las Bancadas", con una función parecida al de las columnas, estaba resuelto con perfiles laminados, ampliando las soluciones experimentadas en el pabellón del Ministerio de la Vivienda, en una solución constructiva muy parecida a la cubierta de Puerta de Hierro II, la segunda vivienda de Cabrero, realizada en

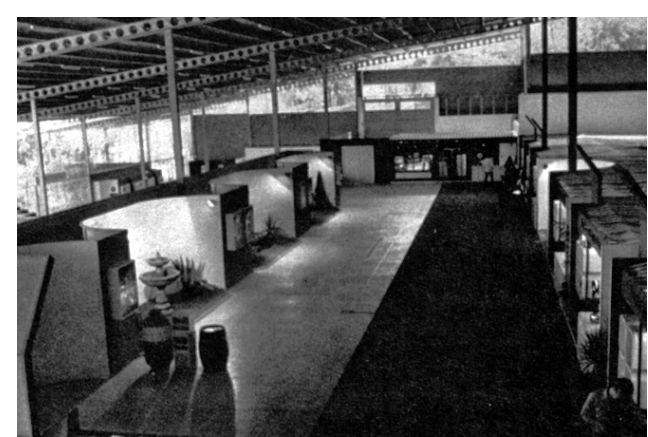

la conocida colonia ese mismo año. También la configuración de bancales y la estructura ligera de cubierta siguiendo el plano inclinado de la ladera recuerda a la residencia de Miraflores proyectada en 1957 por Alejandro de la Sota, José Antonio Corrales y Ramón Vázquez Molezún. El terreno se preparó con bancadas paralelas a las curvas de nivel en dirección este-oeste. El módulo de $11 \mathrm{~m}$ entre columnas era el mismo que el utilizado en el pabellón de la Vivienda, resultando terrazas de $11 \mathrm{~m}$ con longitudes múltiplos, desde 33 hasta $88 \mathrm{~m}$. El desnivel entre las primeras es de $1,50 \mathrm{~m}$, a partir de la quinta bancada este varía al triple y la anchura se duplica, acomodando su contorno a la curva de la cuesta del Arroz. La doble anchura del bancal permite introducir objetos de gran tamaño en el centro de la planta a través de una puerta lateral además de las otras entradas en la parte superior e inferior. En el oeste y el norte, siguiendo el perímetro existente las fachadas también se escalonaban. Sobre las terrazas interiores del edificio se dispuso una cubierta ligera formando un plano inclinado, uniforme y paralelo a la pendiente.

Los pórticos se dispusieron también según la máxima pendiente y se resolvieron con una viga Boyd de $350 \mathrm{~mm}$ situada a cada lado del pilar. Sobre las vigas cada metro se dispusieron las viguetas y una cubierta de placas de fibrocemento onduladas, a $5 \mathrm{~m}$ de altura en las primeras bancadas, hasta los 6,5 $\mathrm{m}$ de altura en la fachada norte, y 8,5 m en la oeste. La visión fragmentada del edificio ocultaba su gran superficie, desapareciendo volumétricamente. Visible desde Madrid y los cerros de la Casa de Campo, el gran plano inclinado y recortado de la cubierta conversa con la abstracta caja del pabellón de Cristal, construido también por Cabrero en 1965. Como ocurría en otros pabellones de la Feria, el cerramiento consistió en un muro ladrillo visto de un pie y medio, que en este caso seguía el escalonamiento de las bancadas sin llegar al plano de cubierta, quedando un hueco perimetral para la entrada de luz y la ventilación natural que se acristalaba en ferias posteriores. Para la VI Feria Internacional, en 1965, se ampliaron ocho módulos, resultando una fachada plana y ciega hacia la explanada de maquinaria, quedando todo el perímetro acristalado bajo la cubierta. En la visita al edificio se puede comprobar cómo el interior resulta más atractivo visto desde abajo, ya que se percibe como una colina ascendente, únicamente delimitada por el plano del techo inclinado (figura 14). 


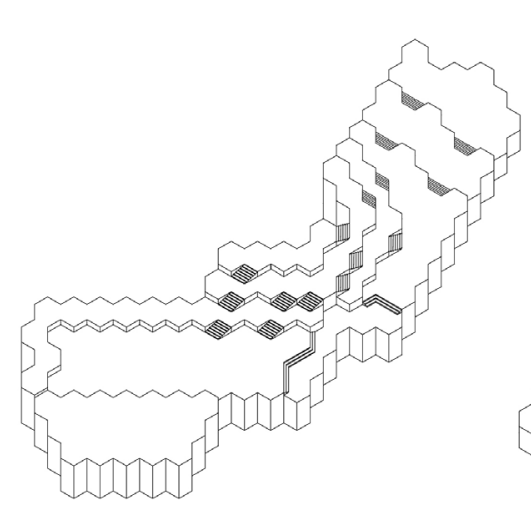

1

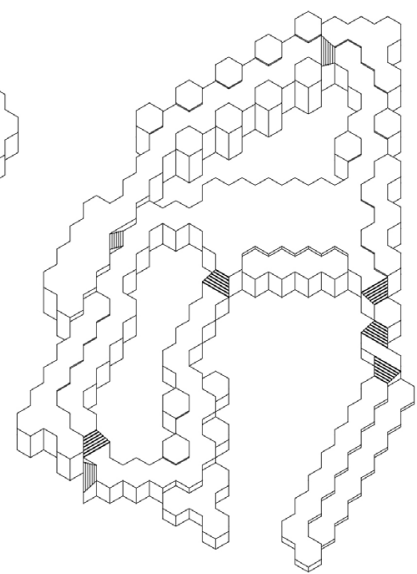

2

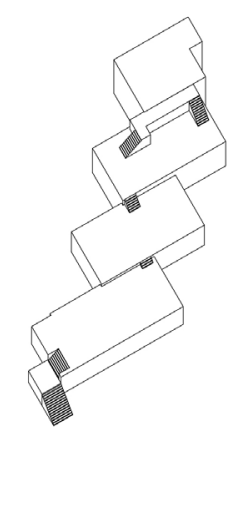

3

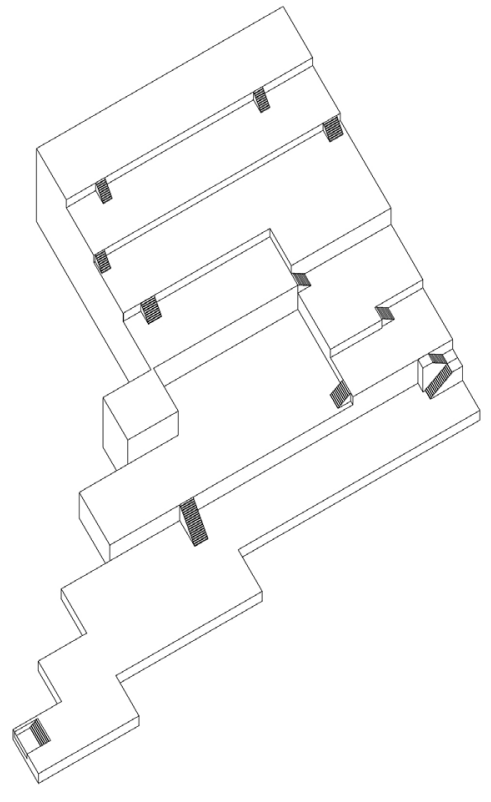

4

\section{Variaciones sobre el bancal: deslizamiento, fragmentación, recorte y cubrición ligera}

Por tanto, el terreno escarpado de la ampliación del recinto ferial inspiró tres soluciones a la construcción en pendiente que sacaban partido de la situación aterrazada, logrando un singular paisaje expositivo al interior (figura 15). En el pabellón del Ministerio de la Vivienda, Francisco Cabrero y Jaime Ruiz proponían un prisma miesiano, un ligero baldaquino que se deslizaba de forma concatenada a lo largo de su lado mayor a la vez que descendía sobre ese mismo plano de fachada, creando al interior un espacio en diagonal tensado por el recorrido lineal definido por las escaleras que conectaban los escalonamientos acompañados por los saltos de las cubiertas horizontales de las cajas. Se definía así un "tubo expositivo" -con entrada en la cota superior y salida en la inferior- que prolongaba el paisaje exterior en terrazas internas paralelas a las curvas de nivel. Las cajas exactas de Mies que Cabrero había conocido en el damero horizontal del campus del IIT en Chicago mutaban así para adaptarse a las tradiciones constructivas de esa España que salía de la autarquía pero también, a las circunstancias particulares del relieve de la Casa de Campo. En un solar de similar pendiente, José Antonio Corrales y Ramón Vázquez Molezún adaptaron la solución de bancales alrededor de la colina de Bruselas a una topografía menos favorable, sacando partido de las posibilidades de fragmentación y adaptación local que el sistema de paraguas hexagonales ofrecía para ceñirse -esta vez en la forma de una mano de dedos y patios- a la geometría el solar y los cambios de cota, respetando las valiosas encinas existentes. Las lecciones de Wright aprendidas de los paraguas del edificio administrativo de la sede de Johnson Wax en Racine, Wisconsin (19361937), pero también de la trama hexagonal de la Honeycomb House para Paul R. and Jean Hanna en Stanford, California (1936-1937) (Gössel y Leuthäuser 1992: 124-126) se traducen en "la nueva instalación de la Casa de Campo" (Cánovas y Bravo: 94) para un cometido distinto que interpreta la relación entre el interior y el exterior a través de los patios dedicados a exposiciones al aire libre. Se generan de este modo unas naves consecutivas en las que los hexágonos rompen con la entrada de luz la homogeneidad del espacio, provocando una sensación laberintica del conjunto frente a la claridad espacial de Bruselas. Por último, el pabellón de las Bancadas traslada al interior diáfano el entorno de bancales paralelos que hace transitable la ladera, apropiándose del paisaje de paratas que da sentido a la propuesta. Aquí, la cubierta no reproduce en el plano superior los saltos discretos de cada terraza, sino que acompaña con un ligero plano inclinado el perfil del desnivel. Este planteamiento desarrolla a lo largo de un eje coincidente con la línea de máxima pendiente la solución ya ensayada por Corrales y Molezún, junto con Alejandro de la Sota, en la residencia infantil para Cristalería Española (figura 16) en Miraflores de la Sierra (1957-1958) (Cánovas y Bravo 1993: 88-91). A
Figura 15. Axonometrias de los bancales: 1 Bruselas; 2 Madrid; 3 Ministerio de la Vivienda; 4 Bancadas. Dibujo del autor. 


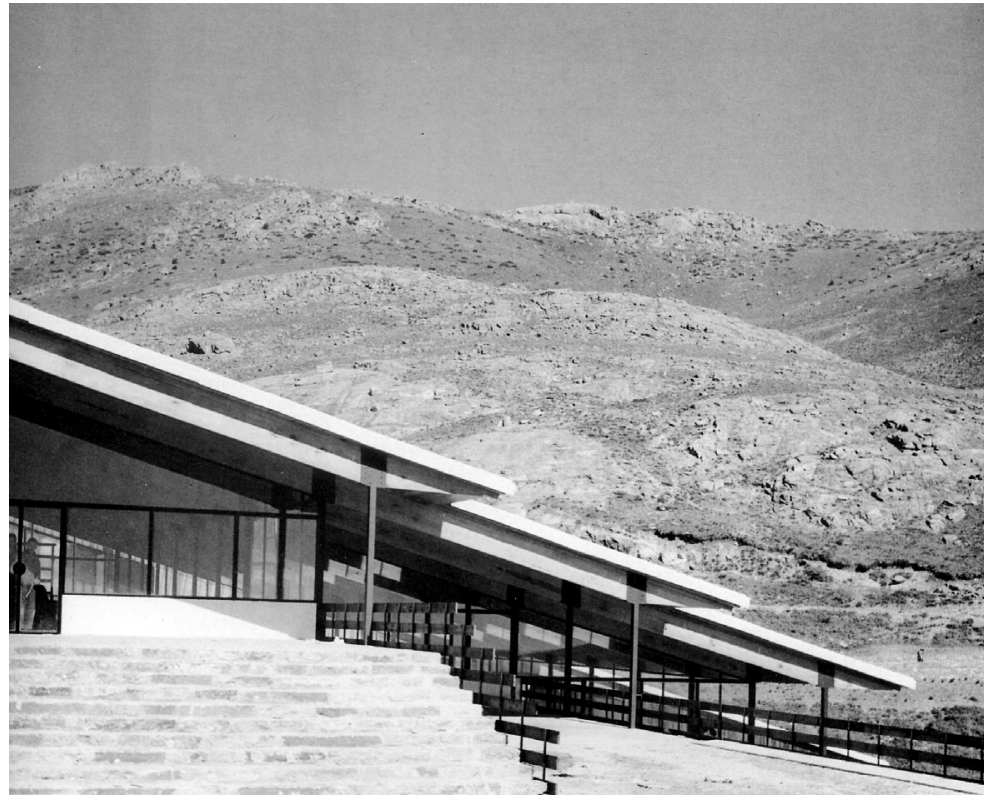

Figura 16. José Antonio Corrales, Ramón Vázquez Molezún y Alejandro de la Sota: residencia de Cristalera Española en Miraflores, 1957 (Sota: 59). partir de la sección tipo de la zona de dormitorios, las tres bancadas de 4,50 m de longitud se escalonan aproximadamente $1,50 \mathrm{~m}$, resultando para esa pendiente, vigas de madera de $6 \mathrm{~m}$ de longitud y $3 \mathrm{~m}$ de separación. Las terrazas se conectan mediante la escalera iluminada cenitalmente, complejizándose el proyecto mediante entreplantas que alojan los baños y vestuarios. Ambos proyectos se desdoblan en una infraestructura ligada a la tierra -compuesta por muros de contención, soleras banqueadas y muros de cerramiento en materiales cerámicos- y un plano ligero de uralita que parece suspendido del aire sobre el moldeado estereotómico del suelo, en una reinterpretación de los muros ciclópeos y las cubiertas estacionales de lona que Wright propuso para su refugio de invierno en Taliesin West, Scottsdale, Arizona (1937) (McCarter 2007: 227-228). La situación más urbana del recinto ferial, con un contorno de parcela condicionado por las calles de acceso, obligaron a recortar las terrazas y con ellas la cubierta para adaptarse a este limite curvo. Por tanto, ante un programa expositivo similar y una topografía en pendiente, los tres pabellones analizados del recinto ferial de la Casa de Campo proponen otras tantas estrategias proyectuales: mediante bandas paralelas a los bancales bajo un plano inclinado, cuando la linea de máxima pendiente coincide con el desarrollo del solar; con prismas que deslizan a lo largo de su cara principal a la vez que descienden, cuando las terrazas se disponen en diagonal respecto a los límites de la parcela y a través de elementos autónomos y dis- cretos capaces de desplazarse y cambiar de cota a lo largo de directrices diversas cuando la topografía desciende en multitud de direcciones. Los edificios aquí analizados se apropian asi del bancal como un paisaje interior mediante operaciones de deslizamiento, fragmentación y recorte, reinterpretando con una economía de mínimos las lecciones de los maestros modernos en el contexto de escasez de la posguerra española.

\section{Notas}

1 Croquis de la I Feria Nacional del Campo. Dibujo de Francisco de Asís Cabrero. (Informes de la Construcción. 1951: 169)

2 El recinto y los pabellones de ganaderos fueron proyectados por Juan Moya e Idigoras. Su sobrino Luis Moya dibujó la entrada principal, el pabellón de administración y las cuadras. (Arquitectura Española 1925: 109)

3 El 20 de abril de 1951 se formaliza el contrato de arrendamiento entre Patrimonio Nacional y la Delegación Nacional de Sindicatos para ampliar la extensión del recinto de 15 a $70 \mathrm{Ha}$. Un punto fundamental fue conseguir la autorización oficial como feria internacional por parte del Ministerio de Industria y Comercio. Acta Comisión ejecutiva de la F.I.C. 25.01.1952. AGA Sindicatos Top 36/58 C4891.

4 Eran 123 edificios según el inventario realizado por el arquitecto Luis Labiano en 1977 (Recinto de la Feria del Campo. Plan General de Actuación 1977).

5 CABRERO, Francisco RUIZ, Jaime. Proyecto de explanación de trincheras en la Feria Nacional del Campo. Madrid, marzo 1952. AGA Sindicatos Top $34 \mathrm{C} 486$.

6 CABRERO, Francisco muros de contención en bancales de exposición de maquinaria. Madrid, diciembre de 1955, y Proyecto de Urbanización en zona de maquinaria ( $2^{\text {a }}$ fase). Madrid, abril 1957. AGA Sindicatos Top 34 C471.

7 CABRERO, Francisco RUIZ, Jaime. Proyecto del pabellón del Ministerio de la Vivienda, primera versión. 1959. Legado Cabrero Fundación COAM.

8 Cartas de José Antonio Corrales a D. Víctor Aranegui, Comisario General de España en la Exposición Universal de Bruselas, 1 de septiembre de 1958, y a Miguel García Sáez, Comisario General de España en la Exposición Universal de Bruselas, 1 de septiembre de 1958, 12 de septiembre de 1958 y 16 de septiembre de 1958. Archivo Corrales.

9 Comunicación personal de José Antonio Corrales al autor, 31 de mayo y 31 de octubre de 2002. 10 Ídem.

11 Corrales, José Antonio; Vázquez Molezún, Ramón. Proyecto de reforma del pabellón de Bruselas para biblioteca y centro cultural, 1991. Arch. Corrales.

12 José Antonio Corrales, comunicación personal al autor, 31 mayo 2002. 


\section{Bibliografia}

La arquitectura de la Feria del Campo. 1959. Hogar y Arquitectura, mayo-agosto 23-24: 86-99.

CABrero, F.; RUIZ, J. 1959. Proyecto del pabellón del Ministerio de la Vivienda. Arquitectura, julio 7: 16-19.

Cabrero, F. 1992. Los cuatro libros de la Arquitectura. Madrid: Colegio Oficial de Arquitectos de Madrid.

CÁnovas, A.; Bravo, R. (eds.). 1993. Corrales y Molezún: Medalla de Oro de la Arquitectura 1992. Madrid, Consejo Superior de Arquitectos de España.

Cánovas, A.; Corrales, J. A. 2005. Pabellón de Bruselas '58. Corrales y Molezún. Madrid: Ministerio de la Vivienda.

Chueca Goitia, F. 1971. Invariantes Castizos de la Arquitectura española. El manifiesto de la Alhambra. Madrid: Seminarios y Ediciones.

Coca Leicher, J. de. 2013. El recinto Ferial de la Casa de Campo de Madrid (1950-75). Tesis doctoral. Universidad Politécnica de Madrid

Corrales, J. A. (ed.). 2005. Pabellón de España en la Exposición Universal de Bruselas 1958, Madrid 1959. Madrid: Rueda.

La Feria del Campo, Madrid (España). 1951. Gran Madrid, 16: 22-24.

III Feria Internacional de Campo, Madrid. 1956. Hogar y Arquitectura, mayo-junio 16: 51-55.

Fernández DEL Amo, J. L. 1969. Nuevo pabellón del Ministerio de Agricultura en la Feria Internacio nal del Campo. Arquitectura, 121 enero: 59-63.

Gössel, P.; Leuthäuser, G. (eds.). 1991. Frank Lloyd Wright. Colonia: Taschen.

LASANTA, T. (et al.). 2013. Los bancales en las montañas españolas: un paisaje abandonado y un recurso potencial. Boletín de la Asociación de Geógrafos Españoles, 63: 301-322.

Mata, S. de la; Sobejano, E. 1987. Entrevista a Francisco de Asís Cabrero. Arquitectura, Madrid, julio-agosto 267: 110-115.

McCARTER, R. 1997. Frank Lloyd Wright. Londres y Nueva York, Phaidon.

Nuevos Cimientos. 1953. Documental 35 mm. Madrid: Delegación Nacional de Sindicatos.

El pabellón de España en la Exposición de Bruselas. 1958. Revista Nacional de Arquitectura, junio 198: 1-10.

Pabellones de la Asociación de Ganaderos de España en la Casa de Campo. 1925. Arquitectura Española, 16: 109.

Patrimonio de bancales en el Mediterráneo occidental: una propuesta de catalogación. 2002. Palma de Mallorca, Consell de Mallorca.

Primera Feria Nacional del Campo. 1951. Informes de la Construcción, enero 27: 169-181.

RÉPARAZ, G. A. de. 1990. La culture en terrasses, expresion de la petite paysannerie méditerranéenne traditionnelle. Méditerranée, 71: 23-29.

Sota, A. 1989. Alejandro de la Sota. Madrid, Pronaos.

Fecha final recepción artículos: 25/04/2019

Fecha aceptación: 18/06/2019

Articulo sometido a revisión por dos revisores independientes por el método doble ciego. 